Bull. Mater. Sci., Vol. 8, No. 4, October 1986, pp. 453-465.

(C) Printed in India.

\title{
Concept of thermodynamic capacity
}

\author{
R AKILA*†, K T JACOB* and A K SHUKLA** \\ *Department of Metallurgy, *†Materials Research Laboratory, \\ **Solid State and Structural Chemistry Unit, Indian Institute of Science, Bangalore \\ 560012 , India. \\ MS received 15 April 1986
}

\begin{abstract}
The thermodynamic capacity of a species $\left(C_{i}\right)$ in a homogeneous phase is defined as $\left(\partial n_{i} / \partial \mu_{i}\right)_{P, T, n_{j}}$ where $n_{i}$ is the total number of moles of $i$ per unit quantity of the system irrespective of the actual system chemistry and $\mu_{i}$ is its chemical potential. Based on this definition, the thermodynamic capacity of oxygen in non-reactive and reactive gas mixtures and in binary and ternary liquid solutions has been computed. For reactive gas mixtures containing stable chemical species which do not undergo significant dissociation such as $\mathrm{CO}+\mathrm{CO}_{2}, \mathrm{H}_{2}+\mathrm{H}_{2} \mathrm{O}$ and $\mathrm{H}_{2}+\mathrm{CO}_{2}$, the capacity curves show a maximum at equimolar ratio and a minimum at higher oxygen potentials. If one of the chemical species partly dissociates as in the case of $\mathrm{H}_{2} \mathrm{~S}$ in $\mathrm{H}_{2}+\mathrm{H}_{2} \mathrm{~S}$ mixtures or $\mathrm{SO}_{3}$ in $\mathrm{SO}_{2}+\mathrm{SO}_{3}$ mixtures, capacity curves do not exhibit such maxima and minima, especially at high temperatures. It would be difficult to produce stable oxygen fugacities when the capacity has a low value, for example at compositions near the minimum. Oxygen capacities of non-ideal liquid solutions, $\mathrm{Cu}-\mathrm{O}$ and $\mathrm{Cu}-\mathrm{O}-\mathrm{Sn}$, and heterogeneous systems formed at saturation with the respective oxides are discussed.
\end{abstract}

Keywords. Thermodynamic capacity; ideal gas mixture; reactive gas mixture; condensed phase.

\section{Introduction}

While the concept of thermodynamic potential is well established and widely used in chemical literature, the corresponding capacity function has not been discussed in the textbooks on thermodynamics (Prigogine and Defay 1954; Swalin 1972; Kestin 1979; Lupis 1983). As such, chemical potentials are appropriate to determine the direction of transport of a species or of a reaction in a chemical system. However, being an intensity factor, chemical potentials do not provide any information on the amount of species transported or on the extent of reaction, even in the absence of kinetic restrictions. A suitably defined capacity factor can be useful in quantifying the amount of a species that can be drawn from a chemical reservoir at a specified chemical potential. Consider, for example, the synthesis of a non-stoichiometric oxide or a Magneli phase at high temperatures by equilibrating the solid with a flowing gas of defined oxygen potential. As oxygen is being added or removed from the oxide, the oxygen potential of the gas phase will usually change. If an $\mathrm{Ar}+\mathrm{O}_{2}$ mixture with $p_{\mathrm{O}_{2}}<10^{-4}$ atm is used for controlling the stoichiometry, the change in oxygen potential of the gas accompanying a finite oxygen exchange with the solid will be very large. In other words, the gas phase is unable to supply or remove any significant amount of oxygen from the solid at a defined potential. The oxygen capacity of the $\mathrm{Ar}+\mathrm{O}_{2}$ mixture may therefore be considered to be low at these low oxygen partial pressures. A gas mixture consisting of $\mathrm{CO}+\mathrm{CO}_{2}$ or $\mathrm{H}_{2}+\mathrm{H}_{2} \mathrm{O}$ may have higher capacity to supply or remove oxygen at low potentials. The purpose of 
this communication is to define thermodynamic capacity and to illustrate its variation for some typical systems. A potential application of the concept in high temperature material synthesis and solid state device research is projected.

\section{Definition of thermodynamic capacity}

Just as the electrical potential increases as electrons are put into a condenser, the chemical potential of a species increases in a homogeneous medium with the addition of that species. While the electrical potential rises linearly with charge, the chemical potential increases logarithmically with concentration for ideal or dilute solutions. The thermodynamic capacity of a species (i) in a homogeneous phase may be defined by the expression,

$$
C_{i}=\left(\partial n_{i} / \partial \mu_{i}\right)_{P, T, n_{j(j \neq i)}},
$$

where $n_{i}$ is the total moles of $i$ in any state of chemical combination per unit amount of the phase and $\mu_{i}$ is the chemical potential of $i$. Thermodynamic capacity of species $i$ may be visualized as the moles of $i$ that is added or removed from a specified quantity of a homogeneous system when the chemical potential of $i$ is given a unit increment or decrement.

It is interesting to explore the variation of thermodynamic capacity with composition for an ideal gas mixture $\left(\mathrm{Ar}+\mathrm{O}_{2}\right)$, reactive gas mixtures usually used in chemical synthesis $\left(\mathrm{CO}+\mathrm{CO}_{2}, \mathrm{H}_{2}+\mathrm{H}_{2} \mathrm{O}, \mathrm{SO}_{2}+\mathrm{SO}_{3}, \mathrm{H}_{2}+\mathrm{CO}_{2}\right.$ and $\left.\mathrm{H}_{2}+\mathrm{H}_{2} \mathrm{~S}\right)$ and condensed phase solutions $(\mathrm{Cu}-\mathrm{O}$ and $\mathrm{Cu}-\mathrm{O}-\mathrm{Sn})$. For simple mixtures, analytical expressions may be derived relating capacity and composition. However, in systems containing several complex species, numerical procedures are more convenient. In the numerical technique, one starts with a preset composition and computes the chemical potential of species $i$. The chemical potential is then incremented by a small amount and the new composition is computed. From the change in composition, the amount of the species added is calculated. The capacity

$$
C_{i}=\Delta n_{i} / \Delta \mu_{i}
$$

\section{Capacity of an ideal gas mixture}

An example of a simple gas mixture is $\mathrm{Ar}+\mathrm{O}_{2}$. In the ideal gas approximation, chemical potential of oxygen in the mixture is given by

$$
\mu_{\mathrm{O}_{2}}=\mu_{\mathrm{O}_{2}}^{\circ}+R T \ln p_{\mathrm{O}_{2}} .
$$

Implicit differentiation gives

$$
\mathrm{d} \mu_{\mathrm{O}_{2}}=\left(R T / p_{\mathrm{O}_{2}}\right) \mathrm{d} p_{\mathrm{O}_{2}} .
$$

The partial pressure of oxygen is defined by

$$
p_{\mathrm{O}_{2}}=n_{\mathrm{O}_{2}} /\left(n_{\mathrm{O}_{2}}+n_{\mathrm{Ar}}\right) \text {. }
$$

This on differentiation gives

$$
\mathrm{d} p_{\mathrm{O}_{2}}=\left(p_{\mathrm{Ar}} / n\right) \mathrm{d} n_{\mathrm{O}_{2}}=\left(p_{\mathrm{Ar}} R T / P V\right) \mathrm{d} n_{\mathrm{O}_{2}},
$$


where $n=n_{\mathrm{O}_{2}}+n_{\mathrm{Ar}}$ is the total moles of oxygen plus argon in the gas and $P$ is the total pressure. Combining (3) and (5), one gets

$$
\mathrm{C}_{\mathrm{O}_{2}}=\frac{\mathrm{d} n_{\mathrm{O}_{2}}}{\mathrm{~d} \mu_{\mathrm{O}_{2}}}=\frac{p_{\mathrm{O}_{2}} P V}{(R T)^{2} p_{\mathrm{Ar}}}=\frac{p_{\mathrm{O}_{2}} P V}{(R T)^{2}\left(P-p_{\mathrm{O}_{2}}\right)}=\frac{p_{\mathrm{O}_{2}} V}{(R T)^{2}\left[1-\left(p_{\mathrm{O}_{2}} / P\right)\right]}
$$

When $p_{\mathrm{O}_{2}} \ll P$, the thermodynamic capacity of oxygen is proportional to the oxygen partial pressure. As $p_{\mathrm{O}_{2}}$ tends to $P$, the infinite capacity of pure oxygen is approached.

In the numerical procedure for the calculation of $\mathrm{C}_{\mathrm{O}_{2}}$, the relative chemical potential is computed for an initial mixture of $n_{\mathrm{O}_{2}}$ moles of $\mathrm{O}_{2}$ and $n_{\mathrm{Ar}}$ moles of $\mathrm{Ar}$ using (4). The chemical potential is then changed by 100 or 1000 cals by addition or removal of oxygen. This changes the number of moles of oxygen in the system by $\Delta n_{\mathrm{O}_{2}}$, which is given by

$$
\Delta n_{\mathrm{O}_{2}}=\frac{\left[p_{\mathrm{O}_{2}}^{\prime}\left(n_{\mathrm{Ar}}+n_{\mathrm{O}_{2}}\right)-n_{\mathrm{O}_{2}}\right]}{\left(1-p_{\mathrm{O}_{2}}^{\prime}\right)}
$$

where $p_{\mathrm{O}_{2}}^{\prime}$ is the new oxygen partial pressure, corresponding to $\mu_{\mathrm{O}_{2}}^{\prime}$. The thermodynamic capacity is given by

$$
\mathrm{C}_{\mathrm{O}_{2}}=\Delta n_{\mathrm{O}_{2}} /\left(\mu_{\mathrm{O}_{2}}^{\prime}-\mu_{\mathrm{O}_{2}}\right)
$$

The calculations have been carried out per mole of the mixture. The variation of $\log C_{\mathrm{O}_{2}}$ with $\log p_{\mathrm{O}_{2}}$ is shown in figure 1 at 1 atm total pressure for different temperatures. Both analytical and numerical techniques give essentially the same result.

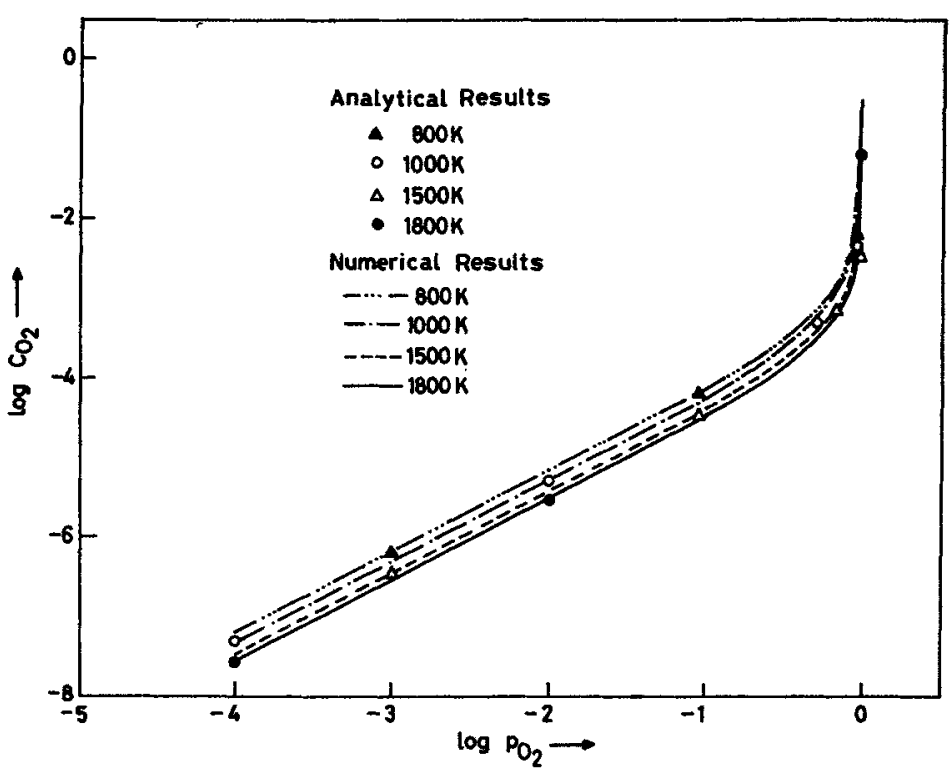

Figure 1. Variation of the thermodynamic capacity, $\mathrm{C}_{\mathrm{O}_{2}}$, with $p_{\mathrm{O}_{2}}$ in $\mathrm{Ar}+\mathrm{O}_{2}$ gas mixture at different temperatures. 


\section{Reactive gas mixtures containing stable species}

\section{$4.1 \mathrm{CO}+\mathrm{CO}_{2}$ mixtures}

In a $\mathrm{CO}+\mathrm{CO}_{2}$ gas mixture, the system is buffered against changes in oxygen potential by the formation or dissociation of $\mathrm{CO}_{2}$ according to the reaction

$$
\mathrm{CC}_{2} \rightarrow \mathrm{CO}+1 / 2 \mathrm{O}_{2} \text {. }
$$

The equilibrium constant $K$ is given by

$$
K=\left(p_{\mathrm{Co}} / p_{\mathrm{CO}_{2}}\right) p_{\mathrm{O}_{2}}^{1 / 2} \text {. }
$$

Based on the approach similar to the one used for an $\mathrm{Ar}+\mathrm{O}_{2}$ mixture, the thermodynamic capacity of oxygen, $\mathrm{C}_{\mathrm{O}_{2}}$, at a given oxygen partial pressure $p_{\mathrm{O}_{2}}$ can be approximated by

$$
\mathrm{C}_{\mathrm{O}_{2}}=\frac{V}{(R T)^{2}}\left[p_{\mathrm{O}_{2}}+\frac{P\left(p_{\mathrm{O}_{2}} / K^{2}\right)^{1 / 2}}{4\left[1+\left(p_{\mathrm{O}_{2}} / K^{2}\right)^{1 / 2}\right]^{2}}\right] \frac{1}{\left(1-p_{\mathrm{O}_{2}} / P\right)}
$$

At $p_{\mathrm{O}_{2}} \simeq K^{2}$ or a $p_{\mathrm{co}} / p_{\mathrm{Co}_{2}}$ ratio equal to unity, $\mathrm{C}_{\mathrm{O}_{2}}$ is a maximum. $\mathrm{A}$ minimum in capacity is observed at a value of $p_{\mathrm{O}_{2}}$ given by

$$
p_{O_{2}} \simeq \frac{1}{4}\left(P^{2 / 3} K^{2 / 3}\right)
$$

or

$$
\frac{p_{\mathrm{CO}_{2}}}{p_{\mathrm{CO}}} \simeq \frac{H}{4}\left(P^{1 / 3} K^{-2 / 3}\right)
$$

In the numerical technique, we consider a starting gaseous mixture of carbon dioxide, carbon monoxide and oxygen with initial number of moles of the species being $n_{\mathrm{CO}_{2}}, n_{\mathrm{Co}}$ and $n_{\mathrm{O}_{2}}$ respectively. The equilibrium composition at a given temperature may be reached by the decomposition of a certain amount of $\mathrm{CO}_{2}$, say $\alpha$, according to the reaction (9). Each of the partial pressures in (10) may be expressed in terms of mole fractions of the particular species. For example

$$
p_{\mathrm{CO}_{2}}=\frac{n_{\mathrm{CO}_{2}}-\alpha}{n_{\mathrm{CO}_{2}}+n_{\mathrm{CO}}+n_{\mathrm{O}_{2}}+\alpha / 2} .
$$

Substituting for the partial pressures in (10), the value of $\alpha$ is given by the solution of the equation

$$
\begin{aligned}
& \alpha^{3}\left(1-K^{2}\right) / 2+\alpha^{2}\left(1-K^{2}\right)\left(n_{\mathrm{O}_{2}}+n_{\mathrm{CO}}\right)+\alpha\left[K^{2} n_{\mathrm{Co}_{2}}\left(3 / 2 n_{\mathrm{CO}_{2}}+2 n_{\mathrm{Co}}+2 n_{\mathrm{O}_{2}}\right)\right. \\
& \left.+n_{\mathrm{Co}}\left(n_{\mathrm{Co}} / 2+2 n_{\mathrm{O}_{2}}\right)\right]-\left[K^{2} n_{\mathrm{CO}_{2}}^{2}\left(n_{\mathrm{CO}_{2}}+n_{\mathrm{CO}}+n_{\mathrm{O}_{2}}\right)-n_{\mathrm{CO}}^{2} n_{\mathrm{O}_{2}}\right]=0 .
\end{aligned}
$$

Let $\Delta n_{\mathrm{O}_{2}}$ be the change in total number of moles of oxygen corresponding to a change in chemical potential by 1000 calories. Equilibrium is reached by the formation of $x$ additional moles of $\mathrm{CO}_{2}$. The new values of the partial pressures are represented as $p_{\mathrm{CO}_{2}}^{\prime}, p_{\mathrm{CO}}^{\prime}$ and $p_{\mathrm{O}_{2}}^{\prime}$. The values of $x$ and $\Delta n_{\mathrm{O}_{2}}$ are then given by the expressions

$$
x=\left(n_{\mathrm{CO}}+\alpha\right)-\frac{p_{\mathrm{CO}}^{\prime}\left(n_{\mathrm{CO}_{2}}+n_{\mathrm{CO}}\right)}{\left(1-p_{\mathrm{O}_{2}}^{\prime}\right)}
$$


and

$$
\Delta n_{\mathrm{O}_{2}}^{\prime}=\left(\frac{n_{\mathrm{CO}}}{2}-n_{\mathrm{O}_{2}}\right)-\frac{\left(n_{\mathrm{CO}_{2}}+n_{\mathrm{CO}}\right)\left(p_{\mathrm{CO}}^{\prime}-2 p_{\mathrm{O}_{2}}^{\prime}\right)}{2\left(1-p_{\mathrm{O}_{2}}^{\prime}\right)}
$$

Hence

$$
\mathrm{C}_{\mathrm{O}_{2}}=\Delta n_{\mathrm{O}_{2}}^{\prime} / \Delta \mu_{\mathrm{O}_{2}}
$$

Two separate cases of $\mathrm{CO}+\mathrm{CO}_{2}+\mathrm{O}_{2}$ mixtures can be considered. In the first case the equilibrium $\mathrm{O}_{2}$ concentration is generated solely by the dissociation of $\mathrm{CO}_{2}$ in a $\mathrm{CO}+\mathrm{CO}_{2}$ mixture. For this case, initial oxygen $n_{\mathrm{O}_{2}}=0$. In the second case, the equilibrium $\mathrm{CO}$ is generated by dissociation of $\mathrm{CO}_{2}$ in a $\mathrm{CO}_{2}+\mathrm{O}_{2}$ mixture and therefore $n_{\text {CO }}=0$.

Case 1: When $n_{\mathrm{O}_{2}}=0$, the expressions (15) and (17) reduce to

$$
\begin{aligned}
& \alpha^{3}\left(1-K^{2}\right) / 2+\alpha^{2} n_{\mathrm{CO}}\left(1-K^{2}\right)+\alpha\left[(3 / 2) K^{2} n_{\mathrm{CO}_{2}}^{2}+2 K^{2} n_{\mathrm{CO}_{2}} n_{\mathrm{CO}}+n_{\mathrm{CO}}^{2} / 2\right] \\
& -K^{2} n_{\mathrm{CO}_{2}}^{2}\left(n_{\mathrm{CO}_{2}}+n_{\mathrm{CO}}\right)=0, \\
& \Delta n_{\mathrm{O}_{2}}=\frac{n_{\mathrm{CO}}}{2}-\frac{\left(n_{\mathrm{CO}_{2}}+n_{\mathrm{CO}}\right)\left(p_{\mathrm{CO}}^{\prime}-2 p_{\mathrm{O}_{2}}^{\prime}\right)}{2\left(1-p_{\mathrm{O}_{2}}^{\prime}\right)} .
\end{aligned}
$$

When $n_{\text {co }}$ is large, $p_{\text {co }}^{\prime}$ is also large, therefore $\Delta n_{\mathbf{O}_{2}}^{\prime}$ is small. As $n_{\text {co }}$ decreases, $p_{\mathrm{CO}}^{\prime}$ also decreases. However, $\Delta n_{\mathrm{O}_{2}}^{\prime}$ increases with decreasing $n_{\mathrm{CO}}$. As the ratio $n_{\mathrm{CO}_{2}} / n_{\mathrm{CO}}$ approaches unity, the value of $\Delta n_{\mathrm{O}_{2}}^{\prime}$ and hence the thermodynamic capacity increases. A maximum value is obtained at a ratio of one. With increasing value of the $n_{\mathrm{CO}_{2}} / n_{\mathrm{CO}}$ ratio, capacity decreases and passes through a minimum. It is difficult to control oxygen potential near the minimum in capacity. Other systems should be considered if it is necessary to control oxygen potential in this range.

Case 2: When $n_{\mathrm{co}}=0$, i.e. at very high oxygen potentials, decomposition of $\mathrm{CO}_{2}$ alone cannot account for the free oxygen in the system. The starting mixture would therefore have $\mathrm{CO}_{2}$ and $\mathrm{O}_{2}$ as the initial species, the $\mathrm{CO}$ content at equilibrium being set up by dissociation of $\mathrm{CO}_{2}$. Then $\alpha$ and $\Delta n_{\mathrm{O}_{2}}^{\prime}$ are given by the solutions of

and

$$
\begin{aligned}
& \alpha^{3}\left(1-K^{2}\right) / 2+\alpha^{2}\left(1-K^{2}\right) n_{\mathrm{O}_{2}}+\alpha\left[(3 / 2) K^{2} n_{\mathrm{CO}_{2}}^{2}+2 K^{2} n_{\mathrm{CO}_{2}} n_{\mathrm{O}_{2}}\right] \\
& -K^{2} n_{\mathrm{CO}_{2}}^{2}\left(n_{\mathrm{CO}_{2}}+n_{\mathrm{O}_{2}}\right)=0
\end{aligned}
$$

$$
\Delta n_{\mathrm{O}_{2}}^{\prime}=\frac{\left(2 p_{\mathrm{O}_{2}}^{\prime}-p_{\mathrm{Co}}^{s}\right) n_{\mathrm{CO}_{2}}}{2\left(1-p_{\mathrm{O}_{2}}^{\prime}\right)}-n_{\mathrm{O}_{2}}
$$

respectively. As $n_{\mathrm{O}_{2}}$ and $p_{\mathrm{O}_{2}}^{\prime}$ increase, the thermodynamic capacity of oxygen increases. For pure oxygen, the capacity will be infinite.

Figure 2 gives the thermodynamic capacity of oxygen as a function of the equilibrium $n_{\mathrm{CO}_{2}} / n_{\mathrm{CO}}$ ratio per mole of gas mixture. The equilibrium constants were taken from the Janaf tables (Stull and Prophet 1971). The values given by the analytic expression (11) and the numerical technique match well. The plot shows a peak at a 1:1 ratio, where the system is buffered well against changes in oxygen potential. At higher oxygen potentials, the capacity coincides with that of an $\mathrm{Ar}+\mathrm{O}_{2}$ mixture as shown in figure 3. The capacity values at $1500 \mathrm{~K}$ are tabulated for various input compositions in table 1 . 


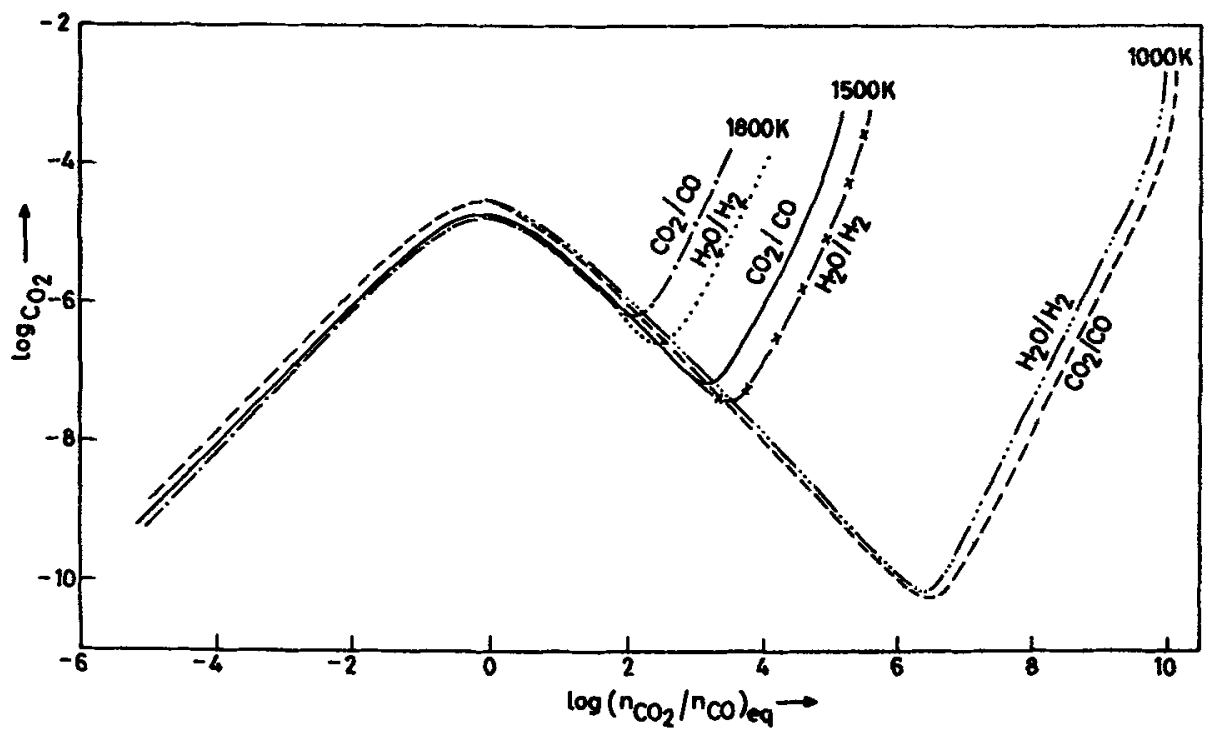

Figure 2. Variation of $\mathrm{C}_{\mathrm{O}_{2}}$ with the equilibrium $n_{\mathrm{CO}_{2}} / n_{\mathrm{CO}}$ or $n_{\mathrm{H}_{2} \mathrm{O}} / n_{\mathrm{H}_{2}}$ ratios at various temperatures.

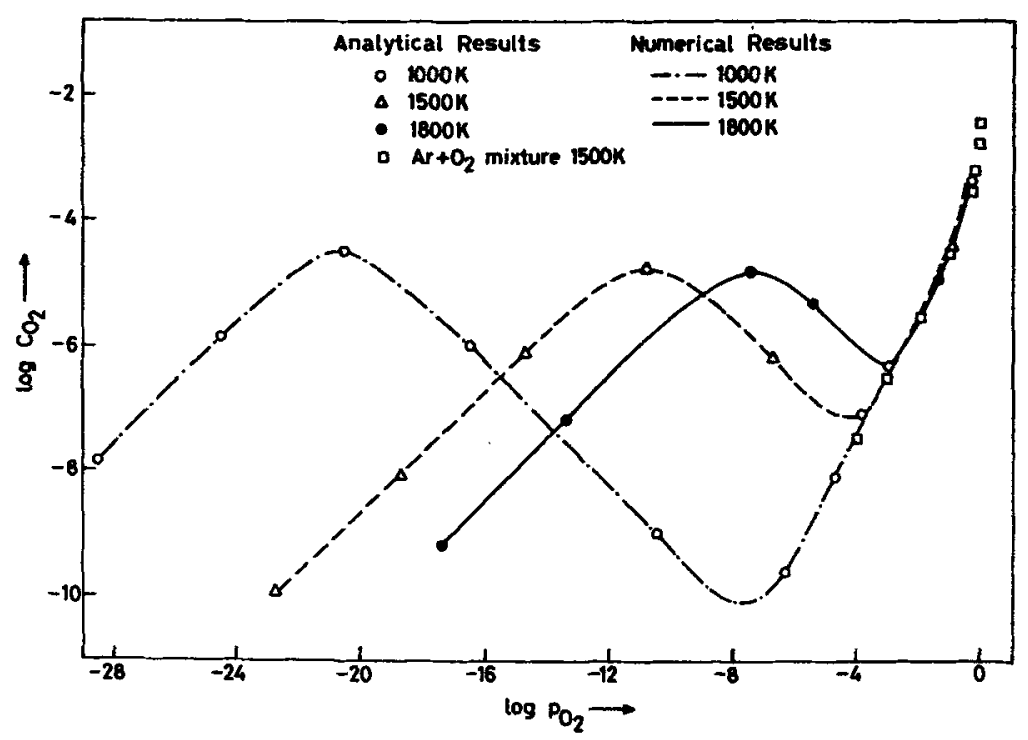

Figure 3. Variation of $\mathrm{C}_{\mathrm{O}_{2}}$ as a function of $\log \mathrm{po}_{2}$ in a $\mathrm{CO}+\mathrm{CO}_{2}$ gas mixture at various temperatures.

\section{$4.2 \mathrm{H}_{2}+\mathrm{H}_{2} \mathrm{O}$ mixtures}

The procedure for calculating $\mathrm{C}_{\mathrm{O}_{2}}$ is similar to that for a $\mathrm{CO}+\mathrm{CO}_{2}$ gas mixture. As seen in figure 2, the small differences in the values of the equilibrium constants for the dissociation reactions in the two gas mixtures give rise to significant differences in the values of $\mathrm{C}_{\mathrm{O}_{2}}$ only at higher oxygen potentials. 
Table 1. Values of thermodynamic capacity of oxygen in a $\mathrm{CO}+\mathrm{CO}_{2}$ mixture for defined values of the equilibrium ratio $n_{\mathrm{CO}_{2}} / n_{\mathrm{CO}}$ in the input mixture at $1500 \mathrm{~K}$, obtained by the numerical technique.

\begin{tabular}{lcl}
\hline$n_{\mathrm{CO}_{2}} / n_{\mathrm{Co}}$ & $p_{\mathrm{O}_{2}} \mathrm{~atm}$ & $\mathrm{C}_{\mathrm{O}_{2}}$ moles $/ \mathrm{cal}$ \\
\hline $10^{-7}$ & $2.13 \times 10^{-25}$ & $1.19 \times 10^{-10}$ \\
$10^{-5}$ & $2.13 \times 10^{-21}$ & $8.94 \times 10^{-10}$ \\
$10^{-3}$ & $2.13 \times 10^{-17}$ & $9.15 \times 10^{-8}$ \\
$10^{-1}$ & $2.13 \times 10^{-13}$ & $7.45 \times 10^{-6}$ \\
1 & $2.13 \times 10^{-11}$ & $2.10 \times 10^{-5}$ \\
10 & $2.13 \times 10^{-9}$ & $6.49 \times 10^{-6}$ \\
$2.59 \times 10^{3}$ & $1.43 \times 10^{-4}$ & $8.72 \times 10^{-8}$ \\
$2.16 \times 10^{4}$ & $9.92 \times 10^{-3}$ & $4.03 \times 10^{-6}$ \\
$6.53 \times 10^{4}$ & $9.09 \times 10^{-2}$ & $4.17 \times 10^{-5}$ \\
$1.53 \times 10^{5}$ & 0.5 & $6.68 \times 10^{-4}$ \\
\hline
\end{tabular}

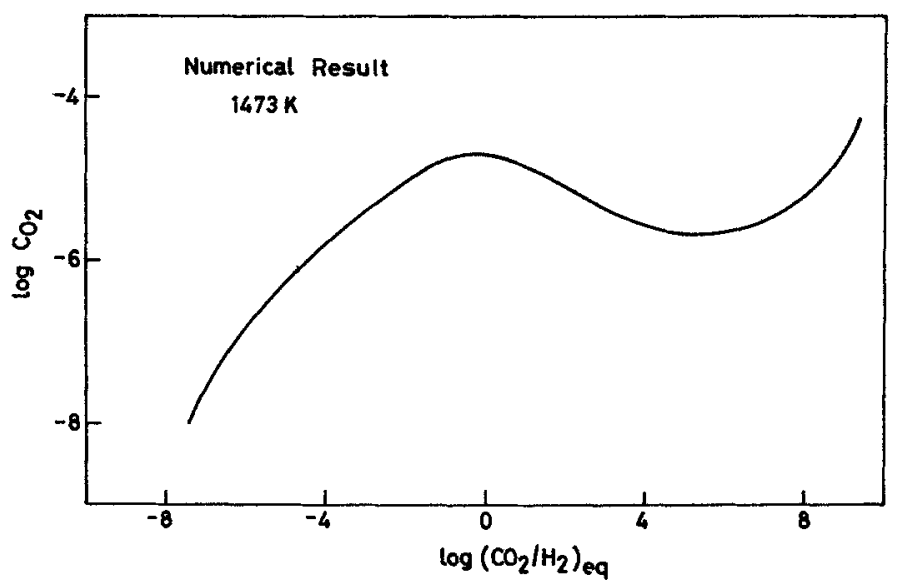

Figure 4. Dependence of $\mathrm{C}_{\mathrm{O}_{2}}$ on $n_{\mathrm{CO}_{2}} / n_{\mathrm{H}_{2}}$ at $1473 \mathrm{~K}$.

\section{$4.3 \mathrm{H}_{2}+\mathrm{CO}_{2}$ mixtures}

The equilibrium gas composition at $1473 \mathrm{~K}$ was calculated considering the species $\mathrm{CO}_{2}, \mathrm{CO}, \mathrm{H}_{2} \mathrm{O}, \mathrm{H}_{2}$ and $\mathrm{CH}_{4}$, using the SOLGAS program (Eriksson 1971). The oxygen capacity was then computed using the numerical procedure. As seen from figure 4 , a peak is seen at a ratio of $n_{\mathrm{CO}_{2}} / n_{\mathrm{H}_{2}}$ equal to unity, at which the equilibrium $n_{\mathrm{CO}_{2}} / n_{\mathrm{CO}}$ and $n_{\mathrm{H}_{2} \mathrm{O}} / n_{\mathrm{H}_{2}}$ values are also close to one. The trend is similar to that for other reactive gas mixtures.

\section{Reactive gas mixtures containing unstable species}

\section{$5.1 \mathrm{SO}_{2}+\mathrm{SO}_{3}$ mixtures}

The equilibrium constant for the decomposition of $\mathrm{SO}_{3}$ is large even at a low temperature of $1000 \mathrm{~K}$. Figure 5 gives the $\mathrm{C}_{\mathrm{O}_{2}}$ values in an $\mathrm{SO}_{2}+\mathrm{SO}_{3}$ mixture as a 


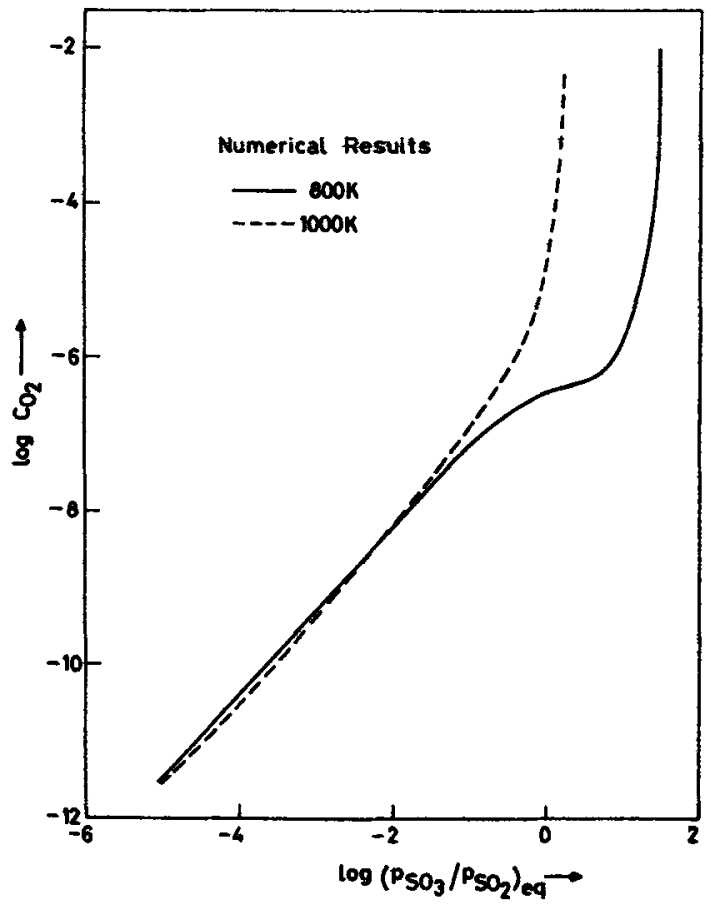

Figure 5. Variation of $\mathrm{C}_{\mathrm{O}_{2}}$ with equilibrium $n_{\mathrm{SO}_{3}} / n_{\mathrm{SO}_{2}}$ in an $\mathrm{SO}_{2}+\mathrm{SO}_{3}$ gas mixture at $800 \mathrm{~K}$ and $1000 \mathrm{~K}$.

function of the equilibrium $n_{\mathrm{SO}_{3}} / n_{\mathrm{SO}_{2}}$ ratio. No peak is observed even at $1000 \mathrm{~K}$ and it is not clearly defined at $800 \mathrm{~K}$. For identical ratios of $n_{\mathrm{SO}_{3}} / n_{\mathrm{SO}_{2}}$ and $n_{\mathrm{CO}_{2}} / n_{\mathrm{CO}}$ at a given temperature, the thermodynamic capacity of oxygen in an $\mathrm{SO}_{2}+\mathrm{SO}_{3}$ mixture is lower.

\section{$5.2 \mathrm{H}_{2}+\mathrm{H}_{2} \mathrm{~S}$ mixtures}

The thermodynamic capacity of sulphur $\mathrm{C}_{\mathrm{S}_{2}}$ in a $\mathrm{H}_{2}+\mathrm{H}_{2} \mathrm{~S}$ gas mixture at temperatures of $800,1000,1500$ and $1800 \mathrm{~K}$ has been calculated on similar lines. The peak again occurs at a ratio of unity as seen in figure 6. At higher temperatures where $\mathrm{H}_{2} \mathrm{~S}$ is unstable, no peak is seen and the capacity continuously increases.

\section{Condensed phase calculations}

In the copper-oxygen system, when oxygen is added to molten copper, its chemical potential rises. However, more oxygen is required at higher potentials to produce a given rise and the capacity increases with increasing oxygen content. While the mathematical equation referring to this curve has no upper limit, there are very real chemical limits. When the oxygen potential exceeds $-32,860$ cals at $1373 \mathrm{~K}, \mathrm{Cu}_{2} \mathrm{O}$ will precipitate as a separate phase. Attempts to increase the oxygen content of molten copper will result in the formation of $\mathrm{Cu}_{2} \mathrm{O}$, which is equivalent to a "leak" at 


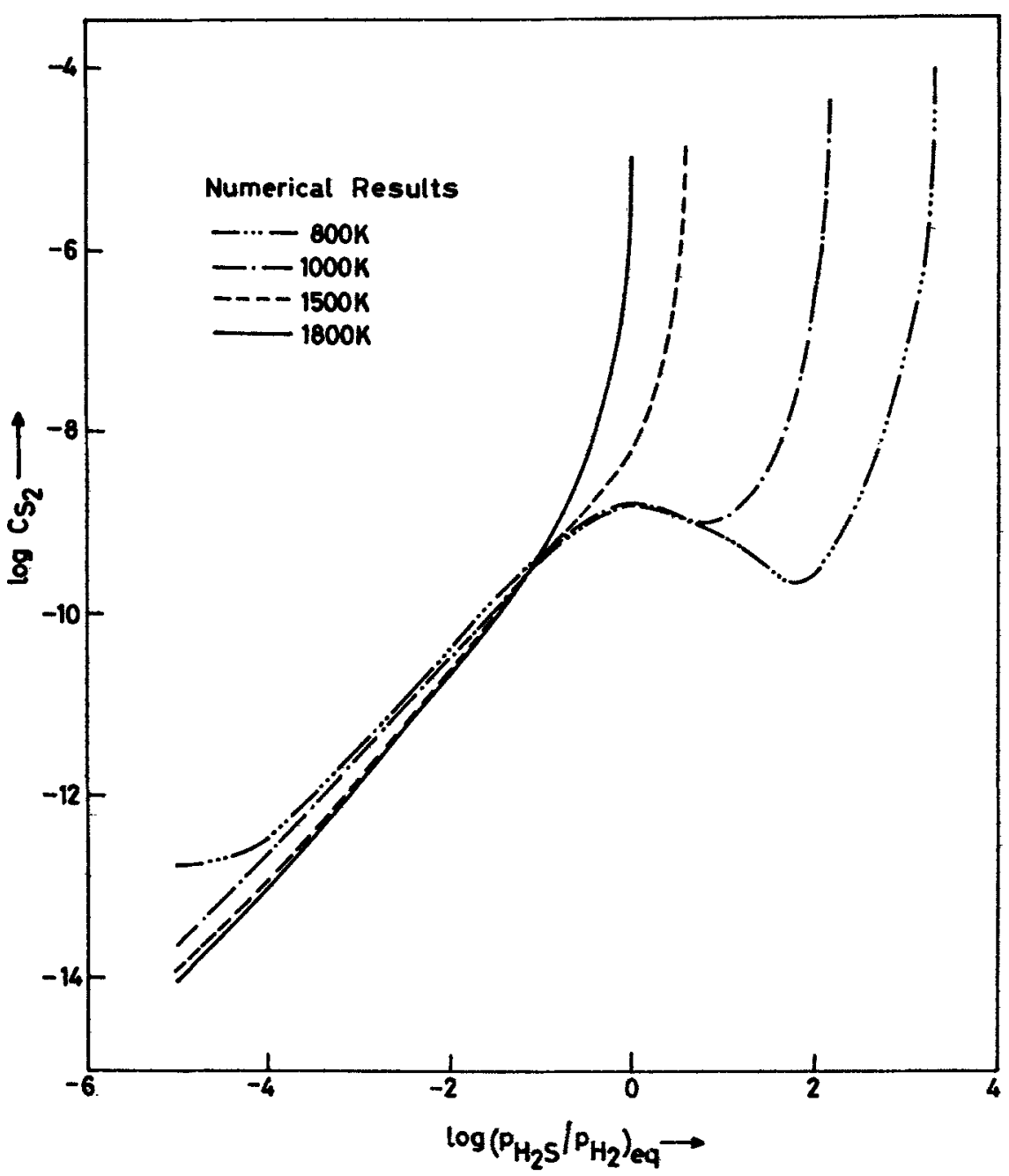

Figure 6. Thermodynamic capacity of sulphur in an $\mathrm{H}_{2}+\mathrm{H}_{2} \mathrm{~S}$ gas mixture at different temperatures.

this level into another phase with unlimited capacity. The whole copper can be oxidized at this potential.

Similarly, if copper contained dissolved tin, it would not be possible to raise the oxygen potential above the value corresponding to the formation of $\mathrm{SnO}_{2}$. The oxygen potential for the formation of $\mathrm{SnO}_{2}$ will be a function of the tin concentration. Here, the leak is to another oxide $\mathrm{SnO}_{2}$. As the tin concentration decreases due to the formation of $\mathrm{SnO}_{2}$ the permissible oxygen potential in the metal goes up. Since the oxygen potential does not remain constant during the formation of $\mathrm{SnO}_{2}$, the capacity does not go to infinity as in the $\mathrm{Cu}-\mathrm{O}$ system, but increases to a very large value at the saturation solubility limit for oxygen at the given tin concentration. 


\subsection{Molten $\mathrm{Cu}-\mathrm{O}$ system}

Dissolution of oxygen in molten copper may be represented by the reaction

$$
1 / 2 \mathrm{O}_{2} \rightarrow[\mathrm{O}]
$$

where $\Delta G^{\circ}$, the free energy change associated with the above reaction is given by (Jacob and Jeffes 1971)

$$
\Delta G^{\circ}=R T\left(\frac{\ln \left(\% O f_{\mathrm{O}}^{\circ}\right)}{p_{\mathrm{O}_{2}}^{1 / 2}}\right)=-20,542+1.723 \mathrm{~T} \mathrm{cal} / \mathrm{g} . \mathrm{at} .
$$

The standard state for dissolved oxygen is chosen such that $a_{\mathrm{O}}=$ atom $\% \mathrm{O}$ as atom $\% \mathrm{O} \rightarrow 0$. The variation of the Henrian activity coefficient of oxygen with concentration at $1373 \mathrm{~K}$ is given by

$$
\log f_{0}^{\circ}=-0.042(\text { at } \% O)
$$

Differentiating (24) with respect to the change in number of moles of oxygen, $\mathrm{d} n_{\mathrm{O}_{2}}$, the thermodynamic capacity, $\mathrm{C}_{\mathrm{O}_{2}}$, is given by the expression

$$
\mathrm{C}_{\mathrm{O}_{2}}=\frac{\mathrm{d} n_{\mathrm{O}_{2}}}{\mathrm{~d} \mu_{\mathrm{O}_{2}}}=\frac{X_{\mathrm{O}_{2}}}{2 R T\left(1+2 \varepsilon_{\mathrm{O}}^{\mathrm{O}} X_{\mathrm{O}_{2}}\right)} \text {, }
$$

where $X_{\mathrm{o}_{2}}$ is the oxygen content in molten copper expressed as a mole fraction of $\mathrm{O}_{2}$ and $\varepsilon_{0}^{O}$ is the self interaction parameter, $\left(\partial \ln f_{\mathrm{o}} / \partial X_{\mathrm{o}}\right)_{X_{\mathrm{o}} \rightarrow 0}$.

In the numerical technique, the equilibrium constant $K$ for (23) given by

$$
K=a_{\mathrm{O}} / p_{\mathrm{O}_{2}}^{1 / 2}
$$

was used to calculate the oxygen partial pressure in equilibrium with a given amount of dissolved oxygen in molten copper. The chemical potential of oxygen was then incremented by 100 cals and the new oxygen content computed. The analytic and numerical results agree well. The saturation solubility limit for oxygen corresponding to the formation of $\mathrm{Cu}_{2} \mathrm{O}$ at $1373 \mathrm{~K}$ is 2.4 atom $\% \mathrm{O}$. As seen from figure 7 , the

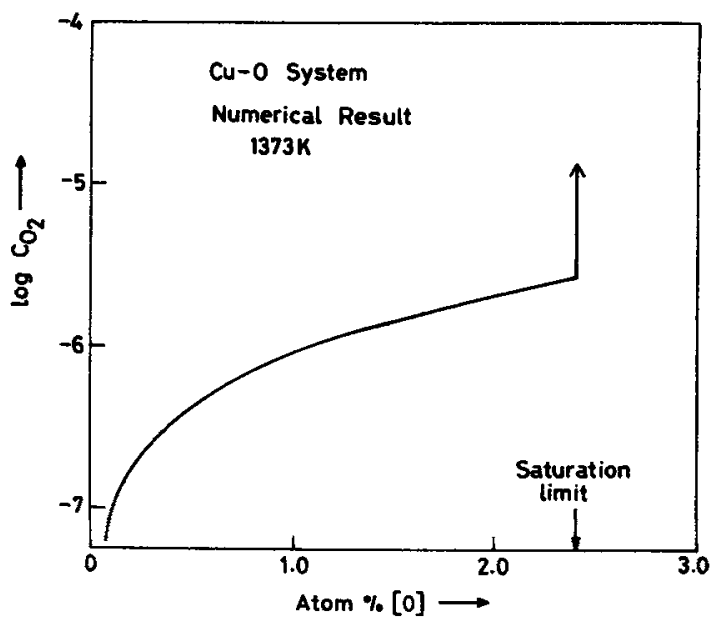

Figure 7. $\mathrm{C}_{\mathrm{O}_{2}}$ as a function of dissolved oxygen in molten copper at $1373 \mathrm{~K}$. 
thermodynamic capacity, $\mathrm{C}_{\mathrm{O}_{2}}$, plotted as a function of dissolved oxygen in copper expressed in atom \% becomes infinite at the saturation value. The phase mixture $\mathrm{Cu}-\mathrm{O}+\mathrm{Cu}_{2} \mathrm{O}$ provides a composition invariant buffer for oxygen.

\subsection{Molten $\mathrm{Cu}-\mathrm{O}-\mathrm{Sn}$ system}

The calculations were done at $1373 \mathrm{~K}$ for various alloy compositions in the range 1-14 atom \% Sn. The interaction parameter $\varepsilon_{0}^{\mathrm{Sn}}$ is (Jacob et al 1970)

$$
\varepsilon_{\mathrm{O}}^{\mathrm{Sn}}=\left(\frac{\partial \ln f_{\mathrm{O}}}{\partial X_{\mathrm{Sn}}}\right)_{X_{\mathrm{Sn}}, X_{\mathrm{O}} \rightarrow 0}=-4 \cdot 6
$$

The corresponding expression for $\log f_{0}$ is

$$
\log f_{\mathrm{o}}=-0.042\left(\text { atom } \% \text { O) }-\frac{4 \cdot 6}{2 \cdot 303} X_{\mathrm{Sn}}\right. \text {. }
$$

The activity coefficient of tin in molten copper is given by (Jacob et al 1970)

$$
\log \gamma_{\mathrm{Sn}}=\left(-1.38+3.333 X_{\mathrm{Sn}}\right) X_{\mathrm{Cu}}^{2}
$$

Combining (24) with the free energy of formation of $\mathrm{SnO}_{2}$, the free energy change for the reaction

$$
\mathrm{Sn}+2[\mathrm{O}] \rightarrow \mathrm{SnO}_{2}
$$

is

$$
\Delta G^{\circ}=-98,566+47 \cdot 174 \mathrm{~T} \mathrm{cal} / \mathrm{mol}
$$

The upper limit to the oxygen activity corresponding to saturation can thus be calculated. The capacity values for various oxygen contents upto the saturation limit were computed by the numerical technique. At saturation, the formation of $\mathrm{SnO}_{2}$ provides an additional sink for oxygen. The analytic expression for capacity of oxygen in saturated solutions of $\mathrm{Cu}-\mathrm{Sn}$ is obtained as shown below:

$$
\begin{aligned}
\frac{\mathrm{d} \mu_{\mathrm{O}_{2}}}{\mathrm{~d} X_{\mathrm{Sn}}} & =\frac{\mathrm{d}}{\mathrm{d} X_{\mathrm{Sn}}}\left(\ln X_{\mathrm{Sn}} \gamma_{\mathrm{Sn}}\right) \\
& =-\frac{R T}{X_{\mathrm{Sn}}}-R T\left(\frac{\mathrm{d} \ln \gamma_{\mathrm{Sn}}}{\mathrm{d} X_{\mathrm{Sn}}}\right) .
\end{aligned}
$$

Now

$$
\mathrm{d} X_{\mathrm{Sn}}=-\mathrm{d} X_{\mathrm{SnO}_{2}}=-\mathrm{d} n_{\mathrm{O}_{2}} \text {. }
$$

Hence

$$
\mathrm{C}_{\mathrm{O}_{2}}=\frac{\mathrm{d} n_{\mathrm{O}_{2}}}{\mathrm{~d} \mu_{\mathrm{O}_{2}}}=\frac{X_{\mathrm{Sn}}}{R T\left\{1+2 \cdot 303 X_{\mathrm{Sn}}\left(1-X_{\mathrm{Sn}}\right)\left(2 \cdot 76+3 \cdot 333\left[1-3 X_{\mathrm{Sn}}\right]\right)\right\}}
$$

At saturation the rise in capacity is by $2-3$ orders of magnitude as shown in figure 8 . The capacity of the two-phase mixture of $\mathrm{SnO}_{2}$ and the homogeneous solution is larger than that of the single phase alloy. The saturation oxygen concentration in the ternary alloy increases as the tin concentration decreases. The oxygen capacity therefore does not go to infinity at saturation. As the tin concentration in the alloy is 


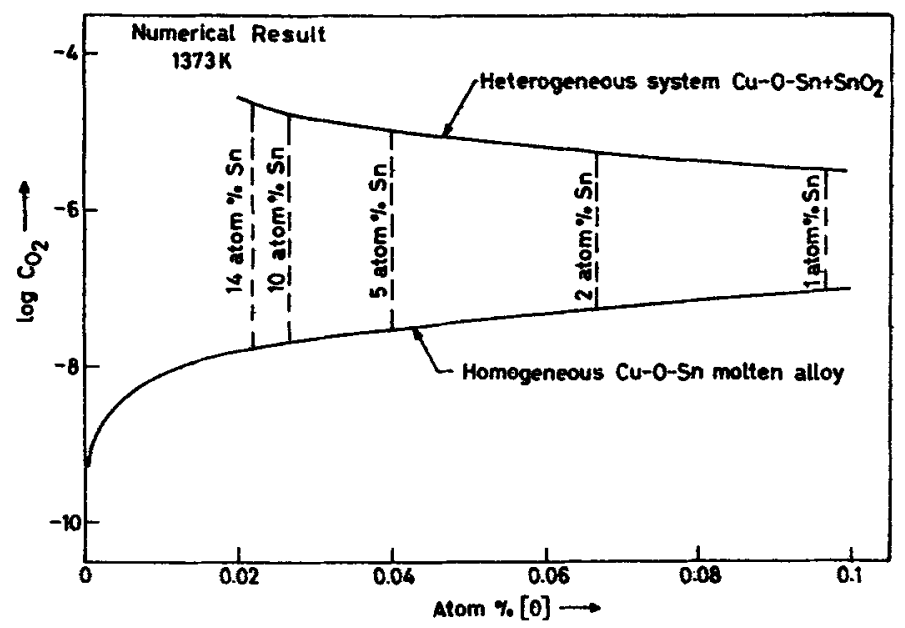

Figure 8. Variation of $\mathrm{C}_{\mathrm{O}_{2}}$ with the concentration of dissolved oxygen in $\mathrm{Cu}-\mathrm{Sn}$ alloys of different compositions at $1373 \mathrm{~K}$.

depleted by the formation of $\mathrm{SnO}_{2}$, the thermodynamic capacity of oxygen varies along the upper curve corresponding to the two-phase mixture. This example illustrates a composition variant two phase buffer.

\section{Applications}

In the preparation of inorganic solids of controlled compositions, the samples are often equilibrated with a gas phase of controlled chemical potential. If the thermodynamic capacity of the gas is low, then a large volume of the gas is required unless the amount of oxygen to be exchanged is small. Similarly, when using gas mixtures containing molecules that differ considerably in molecular weights, as in $\mathrm{H}_{2}+\mathrm{H}_{2} \mathrm{~S}$ mixtures, the flow rate must be kept high to minimize thermal segregation. The experiments using large volumes of high purity gases are inherently expensive. Sometimes disposal of large volumes of toxic gases can also be problematic. A solution to the problem is to use a recirculating system which provides for regeneration of the gas to the required composition. Solid state sensors can be placed in the recirculating stream to ensure that the composition is maintained at preset values. In gas mixtures, for the centrol of oxygen potential, injection or withdrawal of oxygen from the stream can be accomplished by an electrochemical oxygen pump. Coulometric oxygen pumps depend on Faraday's law relating current to oxygen flux and are based on solid electrolytes with mobile oxygen ions. In principle the pump is similar to a sensor. The sensor operates in open circuit mode while the pump operates in the non-zero current mode. The current through the oxygen pump can be regulated by the emf feedback from the solid state sensor. The feedback amplification may be automated. It can be shown that the correct value of the pump current is related to the thermodynamic capacity of oxygen in the gas

$$
\mathrm{I}=\frac{4 F n_{V}}{1-\bar{t}_{e}} \int_{\mu_{\mathrm{o}_{2}}^{\prime}}^{\mu_{\mathrm{O}_{2}}^{\prime}} \frac{\mathrm{C}_{\mathrm{O}_{2}}}{V} \mathrm{~d} \mu_{\mathrm{O}_{2}}
$$


where $n_{V}$ is the volume flow rate of the gas, $\mu_{\mathrm{O}_{2}}^{\prime}$ and $\mu_{\mathrm{O}_{2}}^{\prime \prime}$ are the actual and preset chemical potentials of oxygen in the gas, $\bar{t}_{e}$ is the average electronic transference number of the solid electrolyte and $\mathrm{C}_{\mathrm{O}_{2}} / V$ is the oxygen capacity of the gas per unit volume. The pumping current is a highly nonlinear function of oxygen partial pressure.

\section{Conclusion}

A new thermodynamic variable, thermodynamic capacity, which is a measure of the ability of a chemical system to exchange a species without a change in its chemical potential, has been proposed. The variation of thermodynamic capacity for ideal and non-ideal solutions and systems with strong and weak compounds have been computed using analytical and numerical techniques. The capacities in two-phase heterogeneous systems are illustrated using $\mathrm{Cu}-\mathrm{O}+\mathrm{Cu}_{2} \mathrm{O}$ and $\mathrm{Cu}-\mathrm{O}-\mathrm{Sn}+\mathrm{SnO} \mathrm{O}_{2}$ as examples. Multiphase systems can be devised that have higher thermodynamic capacity than homogeneous phases. The concept of thermodynamic capacity is useful in high temperature chemical vapour transport and solid state devices incorporating electrochemical pumps.

\section{References}

Eriksson G 1971 Acta Chem. Scand. 252651

Jacob K T and Jeffes J H E 1971 Trans. Inst. Min. Metall. C80 32

Jacob K T, Seshadri S K and Richardson F D 1970 Trans. Inst. Min. Metall. C79 274

Kestin J $1979 A$ course in thermodynamics (Washington: McGraw Hill) Vols 1 and 2

Lupis C H P 1983 Chemical thermodynamics of materials (New York: North Holland)

Prigogine I and Defay R 1954 Chemical thermodynamics (London: Longmans, Green and $\mathrm{Co}$.)

Stull D R and Prophet H 1971 JANAF thermochemical tables, 2nd ed. NSRDS-NBS37, U.S. Department of Commerce, Washington D C

Swalin R A 1972 Thermodynamics of solids (New York: John Wiley) 